\title{
MiR-23b targets cyclin G1 and suppresses ovarian cancer tumorigenesis and progression
}

\author{
Jing Yan', Jing-yi Jiang ${ }^{1}$, Xiao-Na Meng ${ }^{1}$, Yin-Ling Xiu ${ }^{2}$ and Zhi-Hong Zong ${ }^{1 *}$
}

\begin{abstract}
Background: It has been proposed that cyclin G1 (CCNG1) participates in p53-dependent $G_{1}-S$ and $G_{2}$ checkpoints and might function as an oncogenic protein in the initiation and metastasis of ovarian carcinoma. MicroRNA 23b (miR-23b) is a critical regulatory factor in the progression of many cancer cell types that targets the relevant genes.

Methods: MiR-23b expression in ovarian tissues was quantified by quantitative reverse transcription-PCR. The ovarian cancer cell lines OVCAR3, HO8910-PM, and SKOV3/DDP were transfected with miR-23b, after we assayed the cell phenotype and expression of the relevant molecules. Dual-luciferase reporter assay and a xenograft mouse model were used to examine the expression of miR-23b and its target gene CCNG1.

Results: MIR23B mRNA expression was significantly lower in epithelial ovarian carcinoma and borderline tumors than in normal ovarian tissues and benign tumors, and miR-23b expression among ages and pathological subtypes was significantly different. CCNG1 mRNA expression was significantly lower in normal ovarian tissues than in benign tumors, borderline tumors, and ovarian carcinomas, and expression among pathological subtypes was significantly different. MiR-23b overexpression inhibited ovarian cancer cell proliferation, invasion, and migration, and induced apoptosis. Dual-luciferase reporter assay showed that miR-23b bound with the $3^{\prime}$ untranslated region of CCNG1. MiR-23b overexpression significantly downregulated CCNG1, urokinase, survivin, BCl-xL, P70S6K, and matrix metallopeptidase-9 (MMP9) mRNA and protein expression. Furthermore, miR-23b inhibited tumor growth and suppressed CCNG1 expression in vitro.
\end{abstract}

Conclusions: Our findings show that miR-23b may inhibit ovarian cancer tumorigenesis and progression by downregulating CCNG1 and the expression of the relevant genes. MiR-23b is a potentially novel application for regulating ovarian carcinoma progression.

Keywords: miR-23b, CCNG1, Ovarian cancer, Tumorigenesis, Progression

\section{Background}

The incidence of ovarian cancer is perpetually high: 200,000 new cases are diagnosed annually worldwide. Each year, it constitutes $4 \%$ of all cancers diagnosed in women, and there are 6.6 new cases per 100,000 women per year [1, 2]. Globally, ovarian cancer caused 160,500 deaths in 2010, an increase from the 113,600 in 1990 and the 140,200 in 2008 [3, 4]. It also remains the most lethal gynecologic malignancy owing to late detection, intrinsic

\footnotetext{
* Correspondence: zongzhi_999@163.com

'Department of Biochemistry and Molecular Biology, College of Basic

Medicine, China Medical University, 100013 Shenyang, China

Full list of author information is available at the end of the article
}

and acquired chemoresistance, and remarkable heterogeneity [5]; recurrence is frequently observed in up to $70 \%$ of cases [6]. In such patients, invasion, metastasis, and chemoresistance may play important roles. Consequently, increasingly sophisticated experiments have been performed to study targeted treatments to improve the 5-year survival rate of patients with ovarian cancer.

MicroRNAs (miRNAs) are a class of small non-coding RNAs that negatively regulate gene expression at posttranscriptional level [7]. It has been demonstrated that a small number of miRNAs actively participate in regulating tumor development; it has been shown that they play different roles in different organs, particularly relating to 
cancer development [8-12]. It has been determined that miR-23b mediates the various steps in the metastatic process, including tumor growth, invasion, and even angiogenesis by repressing a cohort of prometastatic targets [13]. MiR-23b is downregulated in many cancers and acts as a tumor suppressor [14-16]. From a clinical viewpoint, miR-23b has great potential as a diagnostic and therapeutic agent in some tumors. Our previous study showed that miR-23b was highly expressed in normal ovarian tissues than ovarian carcinoma tissues, and our predicted seed region in the 3' untranslated regions (3' UTR) of CCNG1 revealed that it's a target of miR$23 \mathrm{~b}$, thus we investigated the involvement of CCNG1 and miR-23b in ovarian cancer for the first time.

\section{Methods}

\section{Cell culture}

The ovarian cancer cell lines OVCAR3 and HO8910-PM (highly invasive HO8910) were from ATCC. The cisplatin-resistant SKOV3 (SKOV3/DDP) cell line was purchased from the Tumor Cell Bank of the Chinese Academy of Medical Science (Peking, China). The cells were maintained in RPMI 1640 medium supplemented with $10 \%$ fetal bovine serum (FBS), 100 units/mL penicillin and $100 \mu \mathrm{g} / \mathrm{mL}$ streptomycin in a humidified atmosphere of $5 \% \mathrm{CO}_{2}$ at $37^{\circ} \mathrm{C}$.

\section{Proliferation assay}

We used 3-(4,5)-dimethylthiazol (-zyl)-3,5-diphenyltetrazolium bromide (MTT; China) to determine the number of viable cells. Briefly, approximately $2.5 \times 10^{3}$ cells/well were seeded in a 96-well plate and allowed to adhere. At different time points, $20 \mu \mathrm{L}$ MTT solution was added to each well, and the plates were incubated for $4 \mathrm{~h}$. Subsequently, the MTT solution was removed, and $150 \mu \mathrm{L}$ dimethyl sulfoxide was added and incubated for $10 \mathrm{~min}$ before the absorbance was measured at $490 \mathrm{~nm}$.

\section{Cell cycle analysis}

After 48-h incubation, the cells were washed, collected, and fixed in $10 \mathrm{~mL}$ ice-cold ethanol (70\%) for $12 \mathrm{~h}$. Then, the cells were washed, incubated with $5 \mu \mathrm{L}$ RNase $(0.25 \mathrm{mg} / \mathrm{mL})$ at $37{ }^{\circ} \mathrm{C}$ for $30 \mathrm{~min}$, pelleted, resuspended in $50 \mu \mathrm{g} / \mathrm{mL} \mathrm{PI}$, and incubated for $15 \mathrm{~min}$ in the dark at room temperature. Cell cycle analysis was performed by flow cytometric analysis.

\section{Apoptosis assay}

Flow cytometry was performed following PI and FITClabeled annexin V (KeyGen Biotech, Nanjing, China) staining according to the manufacturer's protocol. Briefly, after 48-h incubation, cells were washed and resuspended in $200 \mu \mathrm{L} 1 \times$ binding buffer at $1 \times 10^{6}$ cells $/ \mathrm{mL}$, and incubated with $5 \mu \mathrm{L}$ FITC-annexin V; after 15-min incubation at room temperature in the dark, $300 \mu \mathrm{L} 1 \times$ binding buffer together with $5 \mu \mathrm{L}$ PI were added to each tube. The samples were incubated for $30 \mathrm{~min}$ at room temperature in the dark. Flow cytometry was performed within $1 \mathrm{~h}$.

\section{Wound healing assay}

Cells were seeded at $1 \times 10^{6}$ cells/well in 6-well culture plates. After they had grown to confluence, the monolayer was scratched with a pipette tip $(200 \mu \mathrm{L})$. The cells were washed with PBS three times and cultured in FBS-free medium, and then photographed at 0,24 , and $48 \mathrm{~h}$. The scratched areas were measured using Image J software, after which the wound healing rate was calculated.

\section{Cell invasion assay}

$5 \times 10^{4}$ cells were resuspended in FBS-free medium and seeded into the top chambers of Matrigel $^{\mathrm{ms}}$-coated Transwell ${ }^{\circ}$ inserts (BD Bioscience, San Jose, CA, USA). The lower compartments of the chambers contained $10 \% \mathrm{v} / \mathrm{v}$ FBS as a chemoattractant. After 48-h incubation, the cells on the upper surface of the membrane were wiped away, and the cells on the lower surface of the membrane were washed, fixed, and stained with crystal violet to quantify the extent of invasion.

\section{Ovarian carcinoma specimens}

Specimens from 50 ovarian epithelial carcinomas, 13 benign tumors, 5 borderline tumors, and 6 normal ovarian tissues were collected from patients who underwent surgical resection at the Department of Gynecology of the First Affiliated Hospital of China Medical University (Shenyang, China). Two pathologists confirmed the tumor specimens independently. The China Medical University Ethics Committee approved the study.

\section{Real-time RT-PCR (real-time RT-PCR)}

Real-time RT-PCR was performed from $2 \mu \mathrm{g}$ total RNA using AMV reverse transcriptase and random primers (Takara). The PCR primers were designed according to the GenBank sequences. The glyceraldehyde-3-phosphate dehydrogenase gene (GAPDH) was used as the internal control. The relative gene expression level (the amount of target gene normalized to the endogenous control gene) was calculated using the comparative threshold cycle method: $2^{-\Delta \Delta \mathrm{Ct}}$. Hairpin-it ${ }^{\mathrm{tm}}$ microRNA and U6 snRNA Normalization RT-PCR Quantitation (GenePharma) were used to examine mature miR-23b.

\section{Western blotting}

Proteins were separated by SDS-PAGE, transferred to polyvinylidene difluoride membranes and immunoblotted overnight at $4{ }^{\circ} \mathrm{C}$ with the primary antibodies (1:500), 
rinsed with TBST, and incubated with 1:5000 secondary antibodies conjugated to horseradish peroxidase (Dako). After applying electrochemiluminescence (ECL) Plus detection reagents (Santa Cruz Biotechnology), protein bands were visualized using X-ray film (Fujifilm, Tokyo, Japan). GAPDH-specific monoclonal antibody (1:2000; Santa Cruz Biotechnology) was used as the internal control.

\section{In vivo nude mouse tumorigenicity assay}

The assay was performed to determine the effects of miR$23 \mathrm{~b}$ overexpression on the tumorigenicity of OVCAR3 cells in vivo. Mock or hsa-miR-23b-transfected OVCAR3 cells $\left(1 \times 10^{7}\right)$ were injected subcutaneously into the flanks of 4-6-week-old male nude mice $(n=5)$. Once tumor growth had been established in the mock-treated mice (14 days post-injection), tumor sizes were measured every other day. Tumor volume (mean \pm standard deviation) was calculated as length $\times$ width $^{2} / 2$.

\section{Immunofluorescence (IF) staining}

5 - $\mu \mathrm{m}$ frozen section from each sample was fixed in acetone at $4{ }^{\circ} \mathrm{C}$ overnight. After washing, sections were blocked with $1 \%$ bovine serum albumin for $30 \mathrm{~min}$ and incubated overnight at $4{ }^{\circ} \mathrm{C}$ with rabbit anti-human CCNG1 antibody (1:50). Then sections were incubated with anti-rabbit IgG-FITC (1:100, Santa Cruz Biotechnology) for $2 \mathrm{~h}$ at room temperature in the dark. Nuclei were stained with diaminophenylindole $(1 \mu \mathrm{g} / \mathrm{mL}$; Sigma-Aldrich) for $5 \mathrm{~min}$ at room temperature. Coverslips were mounted and imaged using a laser confocal microscope (Olympus, Tokyo, Japan).

\section{Dual-luciferase reporter assay}

A293 cells were first seeded at $60-80 \%$ confluence in 24-well plates for $12 \mathrm{~h}$. For the dual-luciferase reporter assays, cells were transiently transfected with $\mathrm{Wt}$ or mutated reporter plasmid and miR-23b or control-miR. Firefly luciferase activity was measured using a DualLuciferase Assay (Promega) $48 \mathrm{~h}$ after transfection, and the results were normalized with Renilla luciferase. Each reporter plasmid was transfected at least three times, and each sample was assayed in triplicate.

\section{Statistical analysis}

Statistical evaluation was performed using Spearman's rank correlation coefficient to analyze ranked data; the Mann-Whitney $U$ test was used to differentiate the means of different groups. A $p$-value of $<0.05$ was considered statistically significant. SPSS v. 17.0 (SPSS) was used to analyze all data.

\section{Results}

Correlation of MIR23B and cyclin G1 (CCNG1) mRNA expression with pathogenesis and aggressiveness of ovarian carcinoma

We quantified MIR23B and CCNG1 mRNA expression in normal ovary tissue, benign and borderline tumors, and primary ovarian carcinoma using real-time PCR. MIR23B mRNA expression was significantly lower in the ovarian carcinomas and borderline tumors than in the normal ovarian tissues and benign tumors (Fig. 1a, $p<0.05$ ), and there were significant differences in expression among ages (Fig. 1b, $p<0.05$ ) and pathological subtypes (mucinous vs. other types, Fig. $1 \mathrm{~d}, p<0.05)$. However, there were no significant differences among International Federation of Gynecology and Obstetrics (FIGO) stages (I/II vs. III/ IV, Fig. 1c, $p>0.05$ ) and differentiation (well vs. poor and moderate, data not shown, $p>0.05$ ) in ovarian carcinoma. CCNG1 mRNA expression was significantly lower in the normal ovarian tissues and benign ovarian tumors than in the ovarian carcinomas (Fig. 1e, $p<0.05$ ).

\section{Effects of miR-23b transfection on ovarian carcinoma cell phenotype in vitro}

We transfected OVCAR3, HO8910-PM, SKOV3/DDP cells with miR-23b. The transfected cells exhibited significantly slower growth (Fig. 2a, $p<0.05$ ) but higher levels of mature miR-23b expression than the control and mock-transfected cells (Fig. 2b, $p<0.05$ ). MiR-23b overexpression significant induced $G_{1}$ arrest (Fig. 3a, $p<0.05$ ), higher levels of apoptosis (Fig. 3b, $p<0.05)$ and reduced cell migration (Fig. 4a, $p<0.05$ ) and invasion (Fig. $4 \mathrm{~b}, p<0.05$ ) compared to the control and mock-transfected cells.

\section{Effects of miR-23b transfection on ovarian carcinoma cell genotype in vitro}

The predicted seed region in the 3 ' untranslated regions (3' UTR) of CCNG1 revealed that it is direct target of miR-23b (Fig. 5a); dual-luciferase reporter assay indicated that miR-23b significantly decreased the relative luciferase activity of the wild-type CCNG1 3' UTR as compared with the mutant CCNG1 3' UTR, indicating that miR-23b may directly bind to the 3 ' UTR of CCNG1 (Fig. 5b). Reverse transcription (RT)-PCR (Fig. 5c, p<0.05) and western blotting (Fig. 5d) showed that miR-23b overexpression reduced CCNG1, urokinase (uPA), P70S6K, Bcl-xL, survivin, and matrix metallopeptidase 9 (MMP9) mRNA or protein expression.

\section{MiR-23b inhibited tumor growth in vivo}

The tumor xenograft volume in nude mice treated with miR-23b was smaller than that in the mock-treated mice (Fig. 6a, $p<0.05$ ). From day 4 and week 2 onwards, the 

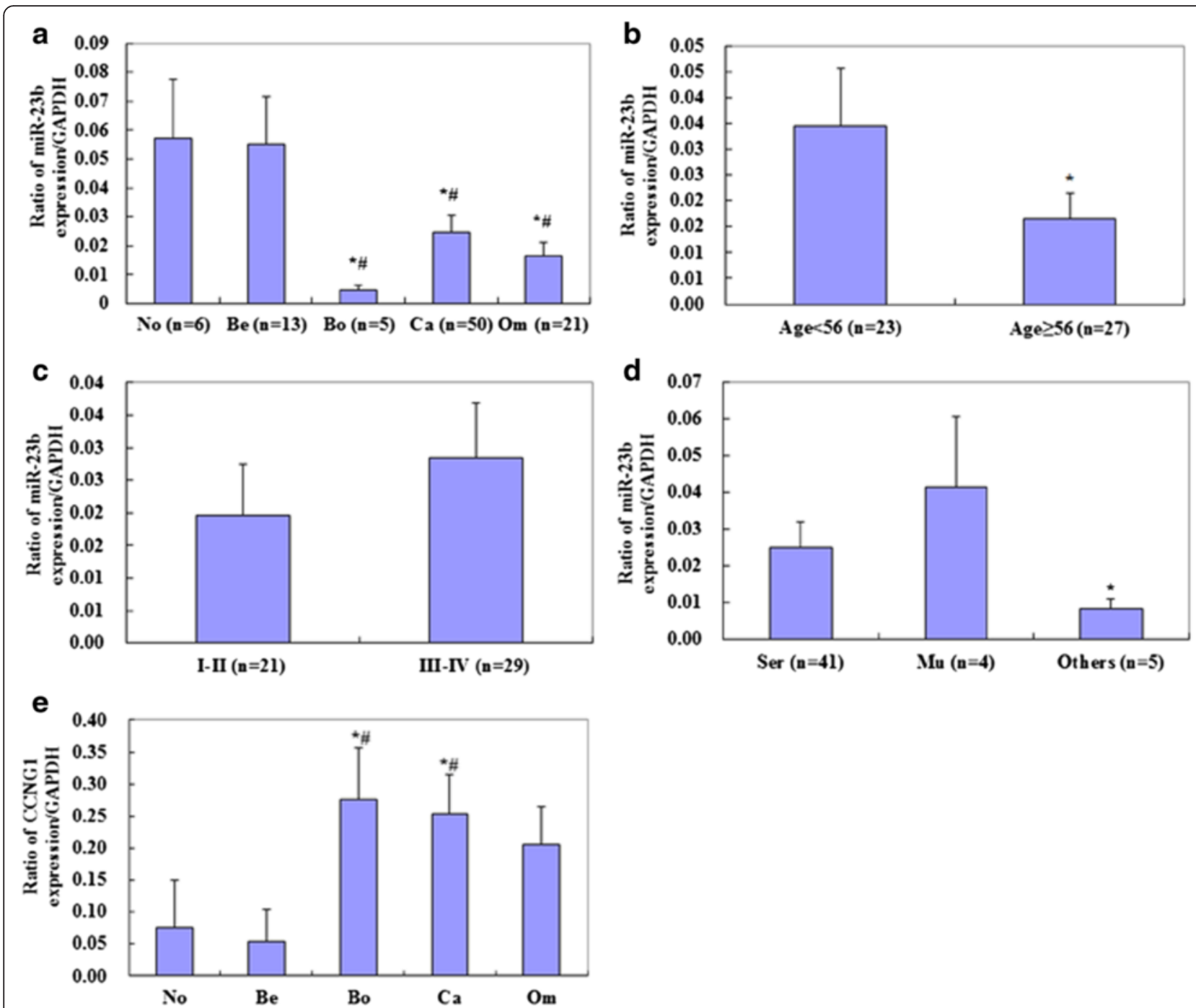

Fig. 1 Correlation of MIR23B and CCNG1 mRNA expression with pathogenesis and aggressiveness of ovarian carcinoma. a MIR23B mRNA expression was significantly lower in the ovarian carcinomas and borderline ovarian tumors than in the normal ovarian tissues and benign tumors; $\mathbf{b}$ there were significant differences in expression among age and $\mathbf{d}$ pathological subtype (mucinous vs. other types) in the ovarian carcinoma tissues. c There were no significant differences among FIGO stage (I/II vs. III/IV) in ovarian carcinoma. e CCNG1 mRNA expression was significantly lower in the normal ovarian tissues and benign ovarian tumors than in the ovarian carcinomas. ${ }^{*} p<0.05$ vs. normal ovarian tissues; $\# p<0.05$ vs. benign ovarian tumors. $\mathrm{No}=$ Normal ovarian tissues, $\mathrm{Be}=$ benign ovarian tumors, $\mathrm{Bo}=$ borderline ovarian tumors, Om $=$ omentum tumors, $\mathrm{Mu}=$ mucinous carcinoma, $\mathrm{Ser}=$ serous carcinoma

tumor xenograft growth in the miR-23b-treated BALB/c mice was slower than that in the mock group (Fig. 6b, $p_{\text {day } 4}<0.05$; $p_{\text {deviation of tumor xenograft volume }[\mathrm{DV}]}<0.01$, and $\left.p_{\text {week } 2}<0.05 ; p_{\mathrm{DV}}<0.01\right)$, and the DV increased in the latter period.

\section{MiR-23b downregulated CCNG1 expression in tumor xenografts in vivo}

Immunofluorescence staining (IF) indicated decreased CCNG1 expression in the tumor xenografts of the miR23b-treated nude mice compared with that in the mock-treated nude mice (Fig. 7).

\section{Discussion}

MiRNAs regulate their target genes by affecting base pairing to their 3' UTRs, resulting in mRNA degradation or inhibition of translation [11]. An increasing number of studies have revealed that miRNAs are promising diagnostic and prognostic molecular biomarkers as well as therapeutic targets in cancer [17, 18]. Series of studies has reported that miR-23b acts as a tumor suppressor in different cancers [19]. Majid et al. showed that miR-23b has diagnostic/prognostic significance and directly targets the oncogenic ZEB1 in bladder cancer [14]. $\mathrm{He}$ et al. reported that miR-23b expression levels in prostate carcinoma $(\mathrm{PCa})$ tissues was significantly correlated 

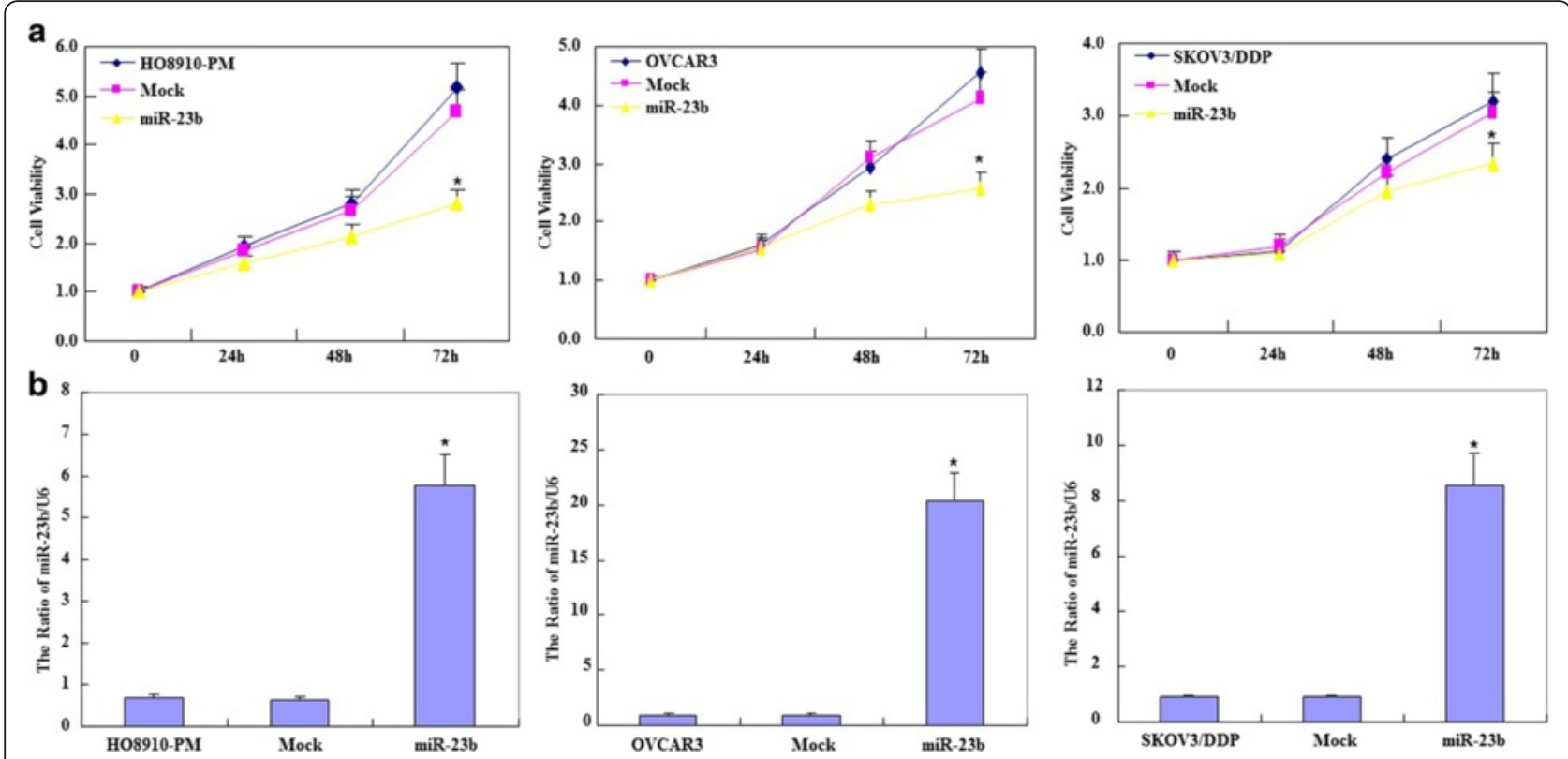

Fig. 2 Effects of miR-23b transfection on ovarian carcinoma cell proliferation in vitro. a Following miR-23b transfection, OVCAR3, HO8910-PM, SKOV3/DDP cell lines exhibited significantly slower growth and $\mathbf{b}$ higher levels of mature miR-23b expression than the control and mocktransfected cells. Results are representative of three separate experiments; data are expressed as the mean \pm standard deviation, ${ }^{*} p<0.05$

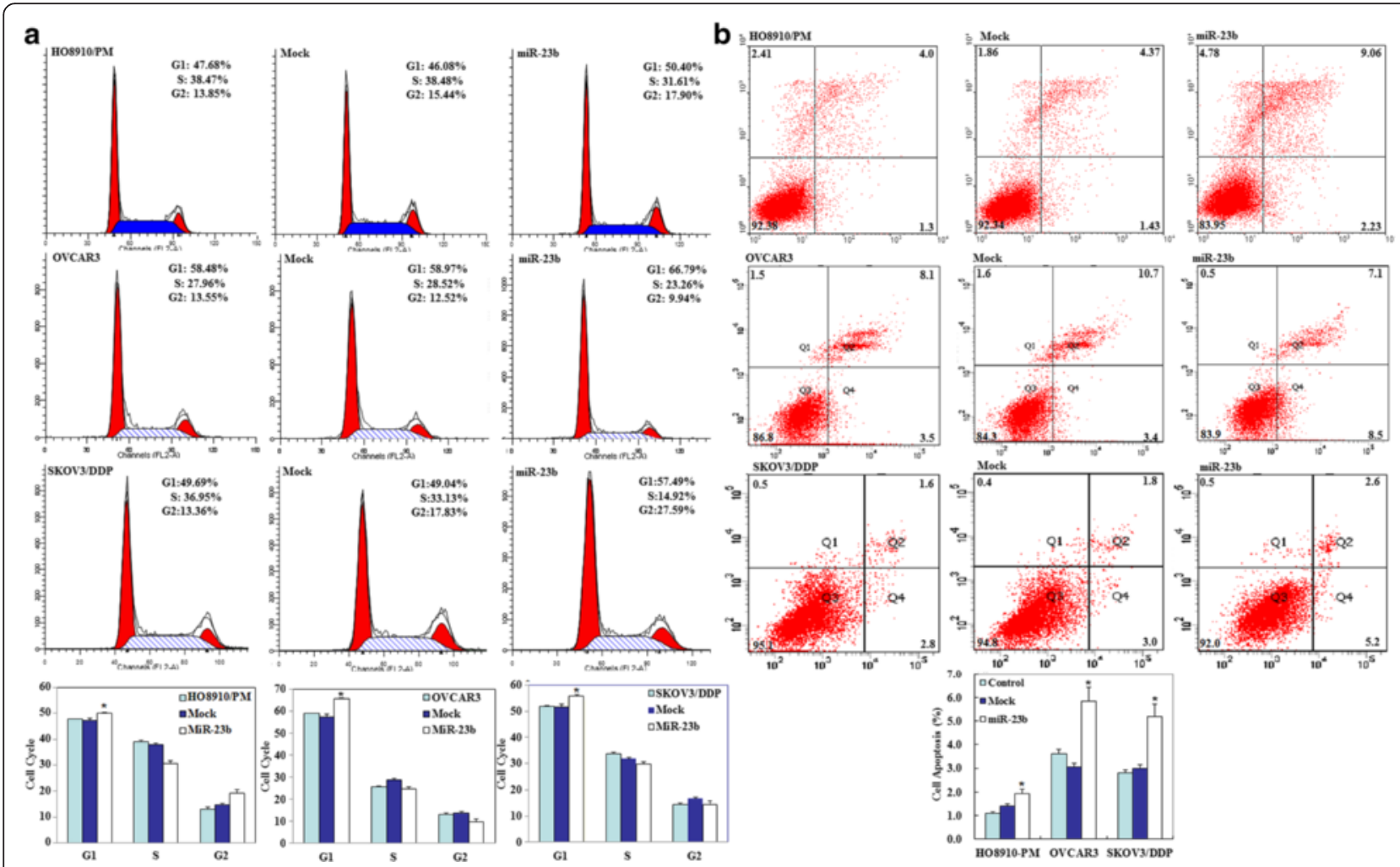

Fig. 3 Effects of miR-23b transfection on ovarian carcinoma cell cycle and apoptosis in vitro. MiR-23b transfection induced $\mathbf{a} G_{1}$ arrest and $\mathbf{b}$ early apoptosis in OVCAR3, HO8910-PM, and SKOV3/DDP cells as compared to the control and mock-transfected cells. Results are representative of three separate experiments; data are expressed as the mean \pm standard deviation, ${ }^{*} p<0.05$ 

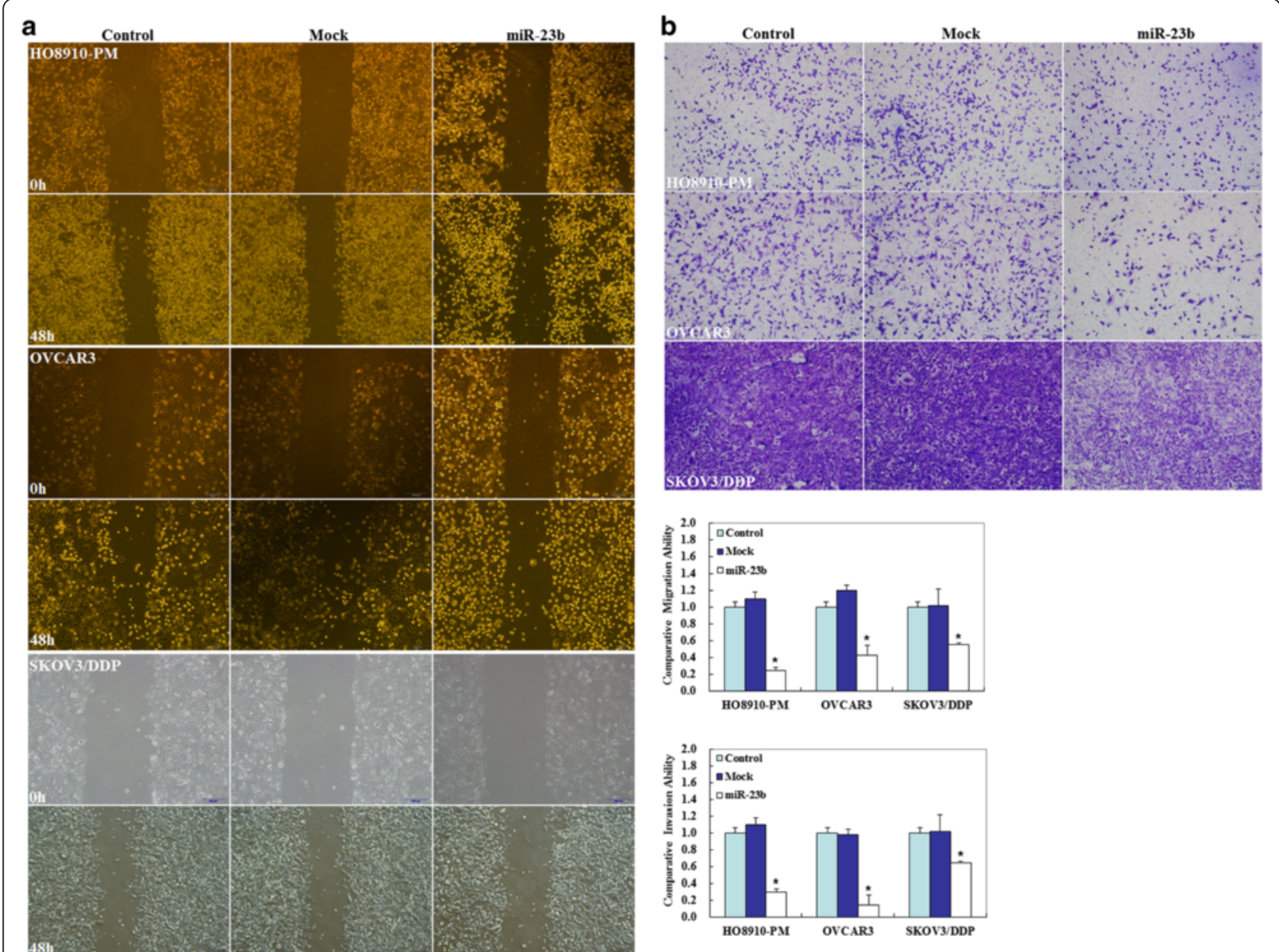

Fig. 4 Effects of miR-23b transfection on the invasive and metastatic ability of ovarian carcinoma cell lines. After transfection with the miR-23b mimic, ovarian carcinoma cells showed $\mathbf{a}$ lower migration and $\mathbf{b}$ slower invasion as compared with the control and mock-transfected cells. Results are representative of three separate experiments; data are expressed as the mean \pm standard deviation, ${ }^{*} p<0.05$

with that of peroxiredoxin $3(P R D X 3)$ and that miR-23b may be involved in the response of PCa cells to hypoxic stress, therefore gene therapy using miRNA mimics may be useful as PCa therapy [20]. Our results show that MIR23B mRNA expression was significantly lower in ovarian carcinomas and borderline tumors than in normal ovarian tissues and benign tumors, and the expression among age and pathological subtypes (mucinous vs. other types) was significantly different. These findings indicate that miR-23b might affect ovarian epithelial carcinogenesis and the subsequent progression. Therefore, we explored the function and molecular mechanism of miR-23b in ovarian cancer cell lines.

Ovarian cancer cells transfected with miR-23b had significantly slower growth than the negative control- and mock-transfected cells, and there was significantly induced $G_{1}$ arrest and apoptosis and reduced cell invasion and migration, suggesting miR-23b may inhibit ovarian carcinoma tumorigenesis and progression. Moreover, the predicted seed region showed that miR-23b targets CCNG1 3' UTR, which was convinced by the dualluciferase reporter assay. We also found that miR-23b transfection decreased CCNG1 mRNA and protein expression. CCNG1 was first identified as a p53-regulated transcript induced by DNA damage. It has been proposed that these events underpin CCNG1 participation in the enforcement of the p53-dependent $G_{1}-S$ and $G_{2}$ checkpoints responsive to DNA damage [21]. Some have suggested that CCNG1 might function as an oncogenic protein $[22,23]$ and play a pivotal role in the initiation and metastasis of hepatocellular carcinoma [24]. Russell et al. reported that CCNG1 amplification is associated with significantly shorter postsurgical survival in patients with ovarian cancer who have received adjuvant chemotherapy with taxanes and platinum compounds [21]. These results suggest that miR-23b may inhibit ovarian cancer tumorigenesis and progression by targeting CCNG1. 


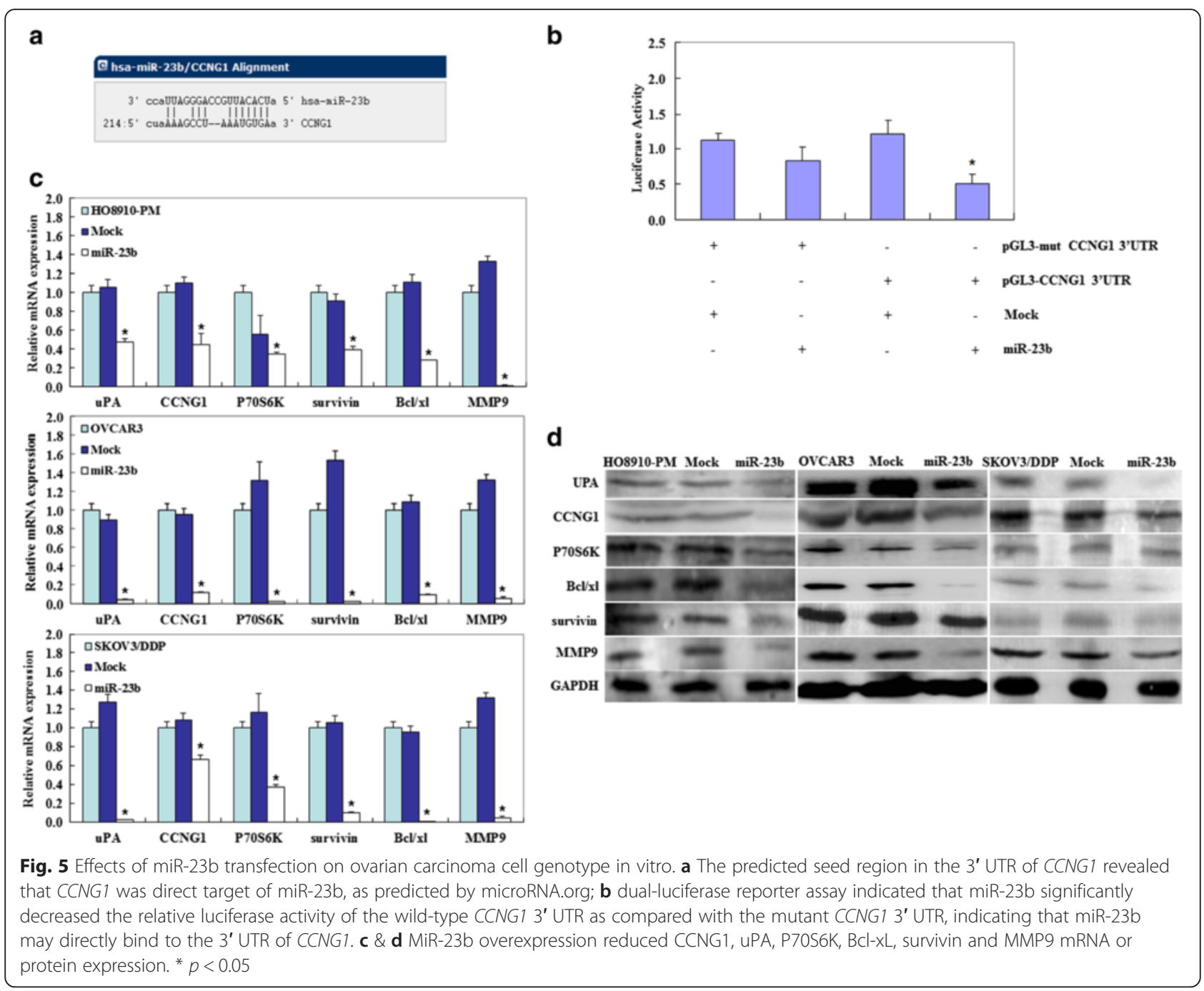

In this study, we also found that miR-23b overexpression downregulated uPA expression, which is in line with the findings of Salvi et al. [15], who reported that miR-23b overexpression leads to uPA downregulation and decreased migration and proliferation ability in hepatocellular carcinoma cells. Furthermore, miR-23b overexpression also downregulated the expression of P70S6K, survivin, Bcl-xL, and MMP9 mRNA and protein. It has been established that UPA is integral to cell differentiation, migration, tissue remodeling under physiological and pathological conditions, and may be a potential diagnostic biomarker and therapeutic target in cancer. Significant elevation of uPA protein levels in primary ovarian cancer tissue has been associated with poor prognosis and disease progression [25-29]. The uPA system plays an important role in many pathophysiological processes, such as cell differentiation, migration, tissue reconstruction, and matrix dissolution [30]. The aberrant expression of phosphorylated P70S6K might contribute to the pathogenesis, growth, invasion, and metastasis of cancer [31]. Wang et al. reported that uPA promoted carcinoma cell proliferation by stimulating P70S6K activation [32]. Survivin, a member of the inhibitors of apoptosis protein family, is expressed during development and in various human cancers. Lee et al. reported that downregulating survivin suppressed uPA through the transcription factor JunB [33]. Ryan et al. reported that survivin expression in breast cancer predicts clinical outcome and is associated with uPA [34]. Furthermore, Zhou et al. reported that Bcl-xL overexpression strongly enhanced uPA in pancreatic ductal adenocarcinoma cells [35]. Therefore, we suggest that miR-23b reduces cell proliferation by downregulating CCNG1 and uPA/P70S6K expression, suppresses cell migration and invasion by downregulating uPA/MMP9 expression, and induces apoptosis by downregulating survivin and Bcl-xL/uPA expression.

We found that CCNG1 mRNA expression was significantly lower in the normal ovarian tissues and benign ovarian tumors than in the borderline ovarian tumors 

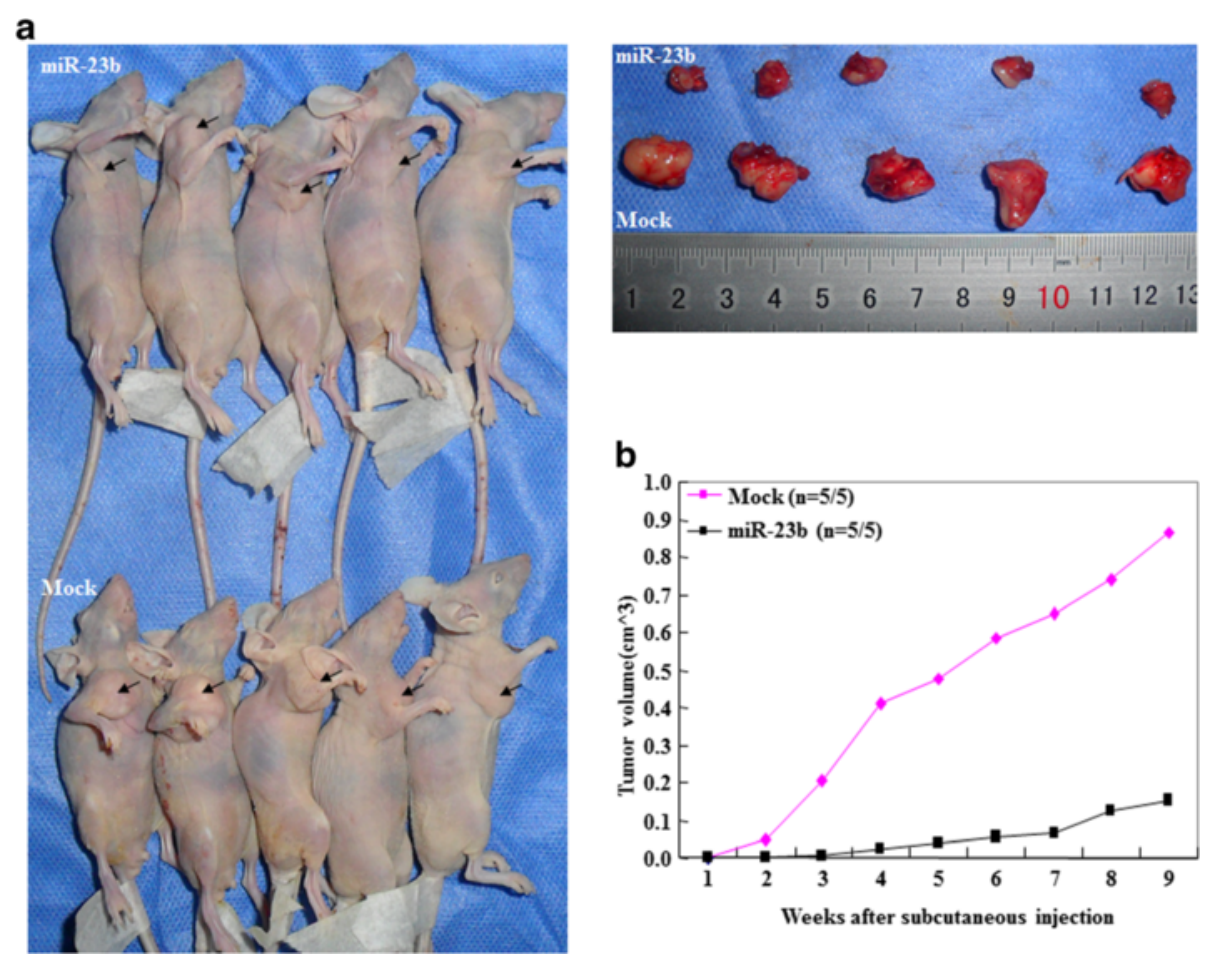

Fig. 6 MiR-23b inhibited tumor growth in vivo. a Tumor xenograft volume in nude mice treated with hsa-miR-23b was smaller than that in mocktreated mice. $\mathbf{b}$ Tumor xenograft growth in miR-23b-treated nude mice was slower than that in the mock group from day 4 and week 2 onwards

and ovarian carcinomas. Our subsequent in vivo tumor xenograft studies showed that miR-23b inhibited tumor growth and decreased CCNG1 expression. Recent studies have reported that CCNG1 gene therapy has been developed and has undergone phase I/II clinical trials for treating colorectal and pancreatic cancer [36]. We suggest that miR-23b may also be a potential suppressor of ovarian carcinoma by targeting CCNG1.

Our findings show that miR-23b may inhibit ovarian cancer tumorigenesis and progression by downregulating CCNG1 and the expression of the relevant genes, and that miR-23b is a potentially novel application for regulating ovarian carcinoma progression.

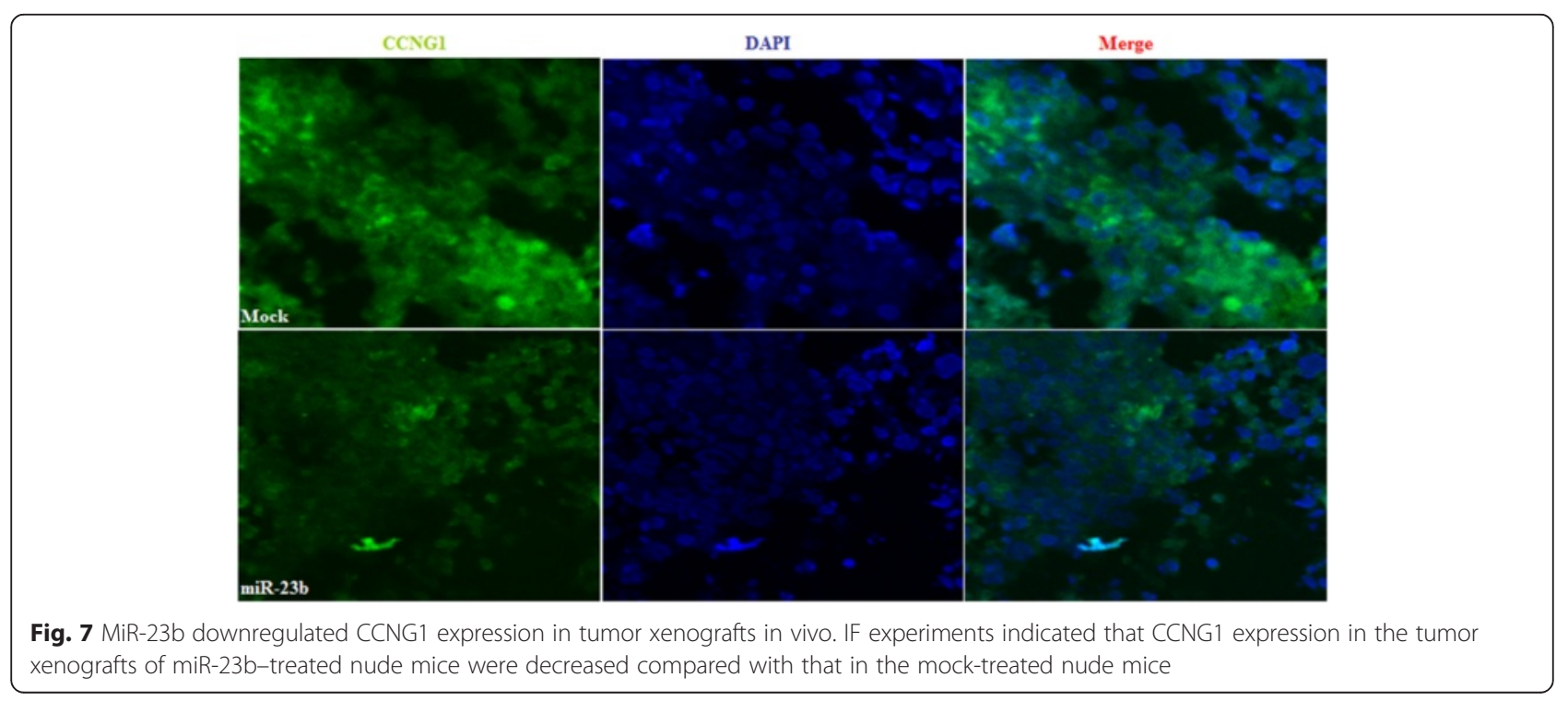




\section{Conclusion}

This is the first demonstration that miR-23b may inhibit EOC tumorigenesis and progression by targeting CCNG1 and modulating the expression of the relevant genes. These findings indicate that miR-23b is a potential suppressor of ovarian carcinoma tumorigenesis and progression. The involvement of miR-23b-mediated CCNG1 downregulation in inhibiting EOC aggressiveness may yield further insight into the molecular mechanisms underlying cancer aggressiveness.

\section{Abbreviations \\ CCNG1: cyclin G1; EOC: epithelial ovarian carcinoma; FIGO stages: International Federation of Gynecology and Obstetrics stages; GAPDH: glyceraldehyde-3-phosphate dehydrogenase gene; IF: immunofluorescent staining; miR-23b: microRNA 23b; MMP9: matrix metallopeptidase-9; MTT: 3-(4,5)-dimethylthiazol (-zyl)-3,5- diphenyltetrazolium bromide; RT-PCR: real-time RT-PCR; SDS-PAGE: sodium dodecyl sulfate-polyacrylamide gel electrophoresis; TBST: tris-buffered saline with tween $20^{\oplus}$}

\section{Competing interests}

The authors declare that they have no competing interests.

\section{Authors' contributions}

$\mathrm{ZH}-\mathrm{Z}$ and $\mathrm{JY}$ carried out the molecular genetic studies, participated in the in vivo tumor xenograft studies, and drafted the manuscript. JY J carried out the immunoassays. XN-M and $Y L X$ participated in the design of the study and performed the statistical analysis. $\mathrm{ZH}-\mathrm{Z}$ conceived the study, participated in its design and coordination, and helped to draft the manuscript. All authors read and approved the final manuscript.

\section{Acknowledgements}

This work was supported by the Natural Scientific Foundation of China (Nos. 81472502), and Liaoning Science and Technology Grant (2013021077).

\section{Author details}

${ }^{1}$ Department of Biochemistry and Molecular Biology, College of Basic Medicine, China Medical University, 100013 Shenyang, China. ${ }^{2}$ Department of Gynecology, The First Affiliated Hospital of China Medical University, 110001 Shenyang, China.

Received: 4 September 2015 Accepted: 4 February 2016 Published online: 13 February 2016

\section{References}

1. Ferlay J, Shin HR, Bray F, Forman D, Mathers C, Parkin DM. Estimates of worldwide burden of cancer in 2008: GLOBOCAN 2008. Int J Cancer. 2010; 127:2893-917.

2. Hannibal CG, Cortes R, Engholm G, Kjaer SK. Survival of ovarian cancer patients in Denmark: Excess mortality risk analysis of five-year relative survival in the period 1978-2002. Acta Obstet Gynecol Scand. 2008;87(12): 1353-60.

3. Lozano R, Naghavi M, Foreman K, Lim S, Shibuya K, Aboyans V, et al. Global and regional mortality from 235 causes of death for 20 age groups in 1990 and 2010: a systematic analysis for the Global Burden of Disease Study 2010. Lancet. 2012;380(9859):2095-128.

4. Chornokur G, Amankwah EK, Schildkraut JM, Phelan CM. Global ovarian cancer health disparities. Gynecol Oncol. 2013;129:258-64.

5. Ahmad N, Kumar R. Steroid hormone receptors in cancer development: a target for cancer therapeutics. Cancer Lett. 2011;300(1):1-9.

6. Eisenkop SM, Friedman RL, Wang HJ. Complete cytoreductive surgery is feasible and maximizes survival in patients with advanced epithelial ovarian cancer: a prospective study. Gynecol Oncol. 1998:69:103-8.

7. Zhang WP, Zhang T, Jin RS, Zhao HC, Hu J, Feng B, et al. MicroRNA-301a promotes migration and invasion by targeting TGFBR2 in human colorectal cancer. J Exp Clin Cancer Res. 2014;33:113.
8. Croce CM. Causes and consequences of microRNA dysregulation in cancer. Nat Rev Genet. 2009:10:704-14.

9. Huang Q, Gumireddy K, Schrier M, le Sage C, Nagel R, Nair S, et al. The microRNAs miR-373 and miR-520c promote tumor invasion and metastasis. Nat Cell Biol. 2008;10:202-10.

10. Ma L, Teruya-Feldstein J, Weinberg RA. Tumor invasion and metastasis initiated by microRNA-10b in breast cancer. Nature. 2007;449:682-8.

11. Tao JQ, Zhi XF, Zhang XY, Fu M, Huang H, Fan Y, et al. miR-27b-3p suppresses cell proliferation through targeting receptor tyrosine kinase like orphan receptor 1 in gastric cancer. J Exp Clin Cancer Res. 2015;34:139.

12. Xiang J, Bian CD, Wang H, Huang SS, Wu DL. MiR-203 down-regulates Rap1A and suppresses cell proliferation, adhesion and invasion in prostate cancer. J Exp Clin Cancer Res. 2015;34:8.

13. Zhang H, Hao Y, Yang J, Zhou Y, Li J, Yin S, et al. Genome-wide functional screening of miR-23b as a pleiotropic modulator suppressing cancer metastasis. Nat Commun. 2011;2:554.

14. Majid S, Dar AA, Saini S, Deng G, Chang I, Greene K, et al. MicroRNA-23b functions as a tumor suppressor by regulating Zeb1 in bladder cancer. PLoS One. 2013:8(7):e67686.

15. Salvi A, Sabelli C, Moncini S, Venturin M, Arici B, Riva P, et al. MicroRNA-23b mediates urokinase and $\mathrm{c}$-met down modulation and a decreased migration of human hepatocellular carcinoma cells. FEBS J. 2009;276:2966-82.

16. Majid S, Dar AA, Saini S, Arora S, Shahryari V, Zaman MS, et al. miR-23b represses proto-oncogene Src kinase and functions as methylation-silenced tumor suppressor with diagnostic and prognostic significance in prostate cancer. Cancer Res. 2012;72:6435-46.

17. Guo J, Wang M, Liu XH. MicroRNA-195 suppresses tumor cell proliferation and metastasis by directly targeting BCOX1 in prostate carcinoma. J Exp Clin Cancer Res. 2015:34:91

18. Kawano M, Tanaka K, Itonaga I, Ikeda S, Iwasaki T, Tsumura H. microRNA-93 promotes cell proliferation via targeting of PTEN in Osteosarcoma cells. J Exp Clin Cancer Res. 2015:34:76.

19. Donadelli M, Palmieri M. Roles for microRNA 23b in regulating autophagy and development of pancreatic adenocarcinoma. Gastroenterology. 2013; 145(5):936-8.

20. He HC, Zhu JG, Chen XB, Chen SM, Han ZD, Dai OS, et al. MicroRNA-23b downregulates peroxiredoxin III in human prostate cancer. FEBS Lett. 2012; 586(16):2451-8

21. Russell P, Hennessy BT, Li J, Carey MS, Bast RC, Freeman T, et al. Cyclin G1 regulates the outcome of taxane-induced mitotic checkpoint arrest. Oncogene. 2012;31:2450-60.

22. Smith ML, Kontny HU, Bortnick Jr R, Fornace AJ. The p53-regulated cyclin G gene promotes cell growth: p53 downstream effectors cyclin G and Gadd45 exert different effects on cisplatin chemosensitivity. Exp Cell Res. 1997;230:61-8.

23. Okamoto K, Prives C. A role of cyclin G in the process of apoptosis. Oncogene. 1999;18:4606-15

24. Wen W, Han T, Chen C, Huang L, Sun W, Wang X, et al. Cyclin G1 expands liver tumor-initiating cells by Sox 2 induction via Akt/mTOR signaling. Mol Cancer Ther. 2013:12(9):1796-804.

25. van der Burg ME, Henzen-Logmans SC, Berns EM, van Putten WL, Klijn JG, Foekens JA. Expression of urokinase-type plasminogen activator (UPA) and its inhibitor PAI-1 in benign, borderline, malignant primary and metastatic ovarian tumors. Int J Cancer. 1996:69:475-9.

26. Kuhn W, Schmalfeldt B, Reuning U, Pache L, Berger U, Ulm K, et al. Prognostic significance of urokinase (UPA) and its inhibitor PAl-1 for survival in advanced ovarian carcinoma stage FIGO IIIC. Br J Cancer. 1999;79(11-12): 1746-51.

27. Konecny G, Untch M, Pihan A, Kimmig R, Gropp M, Stieber P, et al. Association of urokinase-type plasminogen activator and its inhibitor with disease progression and prognosis in ovarian cancer. Clin Cancer Res. 2001;7(6):1743-9.

28. Andreasen PA, Kjøller L, Christensen L, Duffy MJ. The urokinase-type plasminogen activator system in cancer metastasis: a review. Int J Cancer. 1997;72:1-22.

29. Danø K, Andreasen PA, Grøndahl-Hansen J, Kristensen P, Nielsen LS, Skriver L. Plasminogen activators, tissue degradation and cancer. Adv Cancer Res. 1985:44:139-266.

30. Czekay RP, Wilkins-Port CE, Higgins SP, Freytag J, Overstreet JM, Klein RM, et al. PAl-1: an integrator of cell signaling and migration. Int J Cell Biol. 2011;2011:562481.

31. Xiao L, Wang YC, Li WS, Du Y. The role of mTOR and phospho-p70S6K in pathogenesis and progression of gastric carcinomas: an 
immunohistochemical study on tissue microarray. J Exp Clin Cancer Res. 2009;28:152.

32. Wang $X Q$, Sun P, Go L, Koti V, Fliman M, Paller AS. Ganglioside GM3 promotes carcinoma cell proliferation via urokinase plasminogen activatorinduced extracellular signal-regulated kinase-independent p70S6 kinase signaling. J Investig Dermatol. 2006;126:2687-96.

33. Lee KH, Choi EY, Koh SA, Kim MK, Kim KO, Lee SH, et al. Down-regulation of survivin suppresses uro-plasminogen activator through transcription factor JunB. Exp Mol Med. 2011;43(9):501-9.

34. Ryan BM, Konecny GE, Kahlert S, Wang HJ, Untch M, Meng G, et al. Survivin expression in breast cancer predicts clinical outcome and is associated with HER2, VEGF, urokinase plasminogen activator and PAl-1. Ann Oncol. 2006;17: 597-604.

35. Zhou DH, Yang LN, Röder C, Kalthoff H, Trauzold A. TRAlL-induced expression of UPA and IL-8 strongly enhanced by overexpression of TRAF2 and Bcl-xL in pancreatic ductal adenocarcinoma cells. Hepatobiliary Pancreat Dis Int. 2013;12(1):94-8.

36. Morse M. Technology evaluation: Rexin-G, Epeius Biotechnologies. Curr Opin Mol Ther. 2005:7:164-9.

Submit your next manuscript to BioMed Central and we will help you at every step:

- We accept pre-submission inquiries

- Our selector tool helps you to find the most relevant journal

- We provide round the clock customer support

- Convenient online submission

- Thorough peer review

- Inclusion in PubMed and all major indexing services

- Maximum visibility for your research

Submit your manuscript at www.biomedcentral.com/submit
Biomed Central 